\title{
Na praia e no centro: Comércio e serviços de rua frente a operações de requalificação urbana em Salvador-Bahia
}

\author{
At the beach and in the center: street commerce and services facing up to urban \\ requalification operations in Salvador-Bahia
}

\begin{abstract}
Angelo Serpa
Professor titular de Geografia Humana da Universidade Federal da Bahia, Brasil

Bolsista de produtividade em pesquisa do CNPq, nível 1B angeloserpa@hotmail.com
\end{abstract}

Wellington Leite

Graduando do curso de Geografia da Universidade Federal da Bahia, Brasil Bolsista de Iniciação Científica da Fundação de Amparo à Pesquisa do Estado da Bahia - FAPESB wellingtonleite.well@gmail.com

\author{
Juliana Machado \\ Graduanda do curso de Geografia da Universidade Federal da Bahia, Brasil \\ Bolsista de Iniciação Científica do Conselho Nacional de Desenvolvimento Científico e \\ Tecnológico - CNPq \\ juliana.machadogeo@outlook.com
}

\begin{abstract}
Resumo
Este artigo apresenta os resultados de uma pesquisa realizada em Salvador-Bahia, em dois recortes espaciais específicos (Orla /Praia de Piatã e entorno da Estação da Lapa, no Centro Antigo), que objetivou problematizar a presença e a diversidade do comércio e dos serviços de rua e suas táticas de resistência frente a operações recentes de requalificação urbana empreendidas pelo Poder Público Municipal em parceria com a iniciativa privada. Foram aplicados questionários e realizadas entrevistas com comerciantes e prestadores de serviços de rua a fim de caracterizar o perfil destes trabalhadores, bem como seu cotidiano de trabalho em Piatã e no entorno da Estação da Lapa. Buscou-se também analisar esse universo a partir de reflexões embasadas na Teoria dos Dois Circuitos da Economia Urbana (SANTOS, 2004), focando neste segmento específico do Circuito Inferior e em suas relações com o Circuito Superior, assim como com os órgãos públicos de fiscalização e controle. Oscilando entre táticas de territorialização e lugarização (SERPA, 2019), frente às estratégias de requalificação urbana dos poderes públicos, comerciantes e prestadores de serviços de rua se veem ameaçados em seus espaços de trabalho na capital baiana, em um momento de agravamento do desemprego em Salvador e no estado da Bahia.
\end{abstract}

Palavras-chave: Comércio e serviços de rua; Teoria dos dois circuitos da economia; Operações de requalificação urbana; Salvador-Bahia.

\footnotetext{
Abstract

This paper presents the results of a research in Salvador-Bahia, in two specific areas: Estação da Lapa, in the Old Center and Piatã Beach's shore. This study aimed to discuss both the presence and diversity of street commerce and services providers and their resistance tactics against recent urban requalification operations undertaken by Salvador's Municipal Government in partnership with the private sector. Methodologically, questionnaires were applied, and interviews were conducted with traders and street service providers to characterize the profile of these workers, as well as their daily
} 
work routine. It was also sought to analyze this issue through the Theory of Two Circuits of Urban Economy (SANTOS, 2004) - focusing on this specific segment of the Economic Lower Circuit and its relations with the Economic Upper Circuit and with government regulatory agencies. As results, it is shown that traders and street service providers oscillate between tactics of spatialization as territory and place (SERPA, 2019), facing the strategies of urban requalification of the public authorities, and that hawkers and street service labourers are threatened in their workspaces in the Bahian capital (at a time of worsening unemployment in Salvador and the state of Bahia).

Keywords: street commerce and services; Theory of Two Circuits of Urban Economy; urban requalification operations; Salvador-Bahia.

\section{INTRODUÇÃO}

Este artigo busca apresentar os resultados de uma pesquisa que vem sendo realizada nos espaços de uso coletivo em Salvador, submetidos em anos recentes a operações de requalificação urbana, empreendidas pelo poder público municipal ${ }^{1}$. Essas operações vêm alterando a dinâmica das áreas onde são implementadas bem como de seu entorno, afetando, em especial, o comércio e os serviços de rua (SERPA, 2018a).

A estratégia de requalificação urbana atinge não só áreas centrais, como o entorno da Estação da Lapa, maior estação de transbordo da cidade, nó de articulação de significativo número de linhas de ônibus e o metrô de Salvador, mas também áreas turísticas da cidade, com ênfase na orla atlântica soteropolitana, como no trecho da praia de Piatã, localizada ao norte da cidade e local de grande frequentação por parte de baianos e turistas.

Aqui serão apresentados os resultados de nossas pesquisas no entorno da Estação da Lapa e na orla de Piatã, junto aos comerciantes e prestadores de serviços de rua nestes recortes específicos (Figura 1). Nos primeiros seis meses de pesquisa foram aplicados 35 questionários na orla de Piatã e 62 questionários no entorno da Estação da Lapa, esses últimos distribuídos por quatro ruas e duas praças, em ambos os casos a partir de uma amostragem não probabilística por cotas e com utilização de curva de saturação de respostas, obtendo-se, deste modo, uma primeira representação do perfil dos empreendedores de rua e de seus negócios. Nos últimos seis meses de levantamentos foram realizadas entrevistas junto aos comerciantes e prestadores de serviços, com o objetivo de detalhar os dados obtidos com a aplicação de questionários: 12 empreendedores de rua foram entrevistados em Piatã e 18 no entorno da Estação da Lapa.

Esses dados serão problematizados a partir de uma reflexão baseada na relação entre os dois circuitos da economia urbana (SANTOS, 2004), destacando-se um segmento específico do circuito inferior. Busca-se, com isso, ampliar a discussão para além de um pressuposto de

\footnotetext{
${ }^{1}$ Trata-se da pesquisa "Comércio de rua e requalificação de espaços públicos em Salvador-BA: uma abordagem geográfica", desenvolvida desde março de 2018, com o apoio do Conselho Nacional de Desenvolvimento Científico e Tecnológico - CNPq.
} 
"informalidade" e "economia informal" do comércio e dos serviços de rua, enfatizando-se suas relações - de modo geral conflituosas - com o poder público municipal e o circuito superior da economia, bem como os impactos de operações de requalificação urbana nos lugares e territórios (SERPA, 2019) de trabalho dos comerciantes e prestadores de serviços de rua na metrópole soteropolitana.

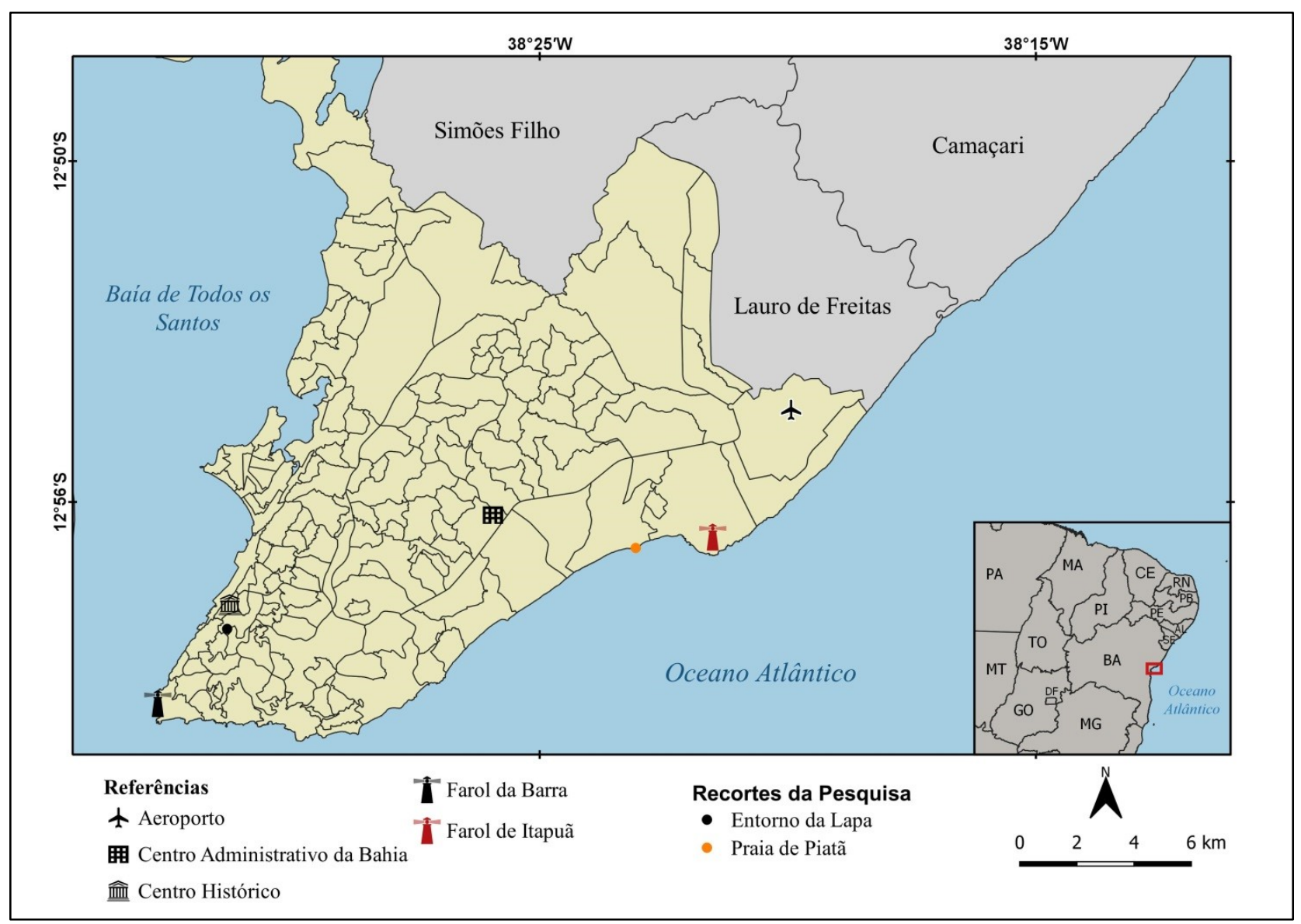

Figura 1 - Localização dos recortes da pesquisa.

Fonte: Autores (2019).

\section{PERFIL E ATUAÇÃO DOS COMERCIANTES E PRESTADORES DE SERVIÇOS DE RUA EM PIATÃ E NO ENTORNO DA ESTAÇÃO DA LAPA}

$\mathrm{Na}$ praia de Piatã esses empreendedores são, em sua maioria, homens, conhecidos popularmente como "barraqueiros" porque trabalham com estruturas semifixas, que incluem equipamentos como toldos, sombreiros, cadeiras e mesas; geralmente de pequeno porte, esses estabelecimentos vendem em geral bebidas que variam de cerveja e refrigerantes a água mineral e água de coco. As mulheres foram identificadas vendendo rifa para os barraqueiros ou trabalhando como "baianas", na venda e na preparação de acarajé e abará.

Em Piatã há uma predominância entre os comerciantes e prestadores de serviços de pessoas com mais de cinquenta anos e que aparentam ter experiência com esse tipo de comércio. Os 
"barraqueiros" apresentam também baixa escolaridade, fato justificado pelos entrevistados pela necessidade de começarem cedo nessa atividade ou em outras similares; alegam que a vontade de continuar a estudar foi se dissipando com o tempo, quando começaram a trabalhar na praia, o que envolve uma atuação mais braçal e trabalho predominantemente manual. 3\% dos barraqueiros pesquisados nunca estudaram e metade deles não concluiu sequer o ensino fundamental.

A grande maioria destes comerciantes e prestadores de serviços reside em bairros próximos de Piatã, como Itapuã, por exemplo. A proximidade do local de residência ajuda na logística do trabalho diário dos "barraqueiros", já que eles precisam retirar suas estruturas semifixas todo dia ao final do serviço e muitos deles não usufruem de um local para guardar seus equipamentos, como containers na calçada em Piatã ou depósitos próximos; por isso, precisam levar diariamente os equipamentos e as mercadorias que não foram vendidas para sua residência. Morando perto de Piatã, há maior facilidade para transportar seu material de trabalho para casa.

Mais de 50\% dos comerciantes e prestadores de serviços entrevistados em Piatã trabalham como barraqueiros há mais de dez anos. 36\% trabalham assim há mais de vinte anos. Esse fato, analisado em conjunto com outros dados obtidos através da aplicação dos questionários, reforça o perfil de trabalhadores com experiência nesse ramo: ao serem questionados se queriam mudar de ocupação, a resposta negativa foi quase unânime entre os "barraqueiros" pesquisados, que justificam a permanência ali por sua baixa escolaridade (o que torna difícil uma mudança), mas também pelo prazer de estarem trabalhando na praia, usufruindo da paisagem e dos elementos naturais. A fixidez desses comerciantes e prestadores de serviços mostra que muitos deles já estavam trabalhando com essa atividade quando ainda existiam as barracas fixas em Piatã, continuando ali após sua demolição em 2010. Agora, com as estruturas semifixas, eles permanecem no mesmo ponto, trazendo o questionamento sobre que tipo de relação eles desenvolveram ao produzir aquele espaço, se como "lugar" ou como "território".

As opções de comprar diretamente nas cervejarias, nos depósitos ou no comercio atacadista é a alternativa buscada pela maioria, mesmo sendo usufruída de uma maneira específica: Eles não precisam se deslocar para adquirir os produtos, esses serviços vão até a praia e fazem a entrega das mercadorias diretamente aos "barraqueiros". Há aqui uma ligação clara e uma relação de dependência mútua entre o circuito inferior e o circuito superior da economia, como analisado por Santos (2004). Outra opção é comprar com os vendedores ambulantes, que caminham na praia vendendo produtos como coco e cerveja, transportados com carrinho de mão ou mesmo carregando as mercadorias durante o trajeto, em geral com um preço mais acessível.

A resposta que prevalece entre estes comerciantes e prestadores de serviços é a de que pagam uma taxa para a prefeitura de Salvador para ocupar um espaço delimitado na areia, colocar suas estruturas semifixas e comercializar seus produtos, através do DAM (Documento de 
Arrecadação Municipal). Aqui fica claro que a maioria dos "barraqueiros" não pode ser caracterizada como "informal”, embora apresente características do circuito inferior da economia (SANTOS, 2004; MAIA, 2013). O pagamento ocorre mensalmente e varia na metade das respostas entre duzentos e cinquenta e um e trezentos reais. Constatou-se que alguns deles não são os donos do ponto, ou seja, não é o nome deles que consta na documentação do DAM: desse modo, desenvolveram uma relação de aluguel, pagando um valor a mais aos titulares das estruturas. Há também aqueles que não pagam a taxa há muito tempo e por essa razão não sabem responder sobre os valores de modo mais preciso.

O trabalho na praia geralmente acontece durante o dia, nos meses de verão, e, em tempos chuvosos, a venda diminui drasticamente. Também enfrentam outros problemas como, por exemplo, falta de água doce, escassez de banheiros químicos, conflitos entres os comerciantes e prestadores de serviços que efetuam o pagamento da taxa e aqueles que não fazem o pagamento. Estes últimos colocam suas estruturas próximas das mesas dos barraqueiros pagantes e vendem bebidas a um custo mais baixo. Alguns dos "barraqueiros" nos explicam o porquê das dificuldades que tiveram para responder sobre sua renda, com a justificativa de que não fazem o controle de quanto recebem ou gastam com seu trabalho. As respostas a essa questão variaram entre 10 e 200 reais de lucro líquido diário.

Com relação ao perfil dos comerciantes do entorno da Estação da Lapa, observou-se que há uma variedade consideravelmente alta entre as faixas etárias e o sexo desses comerciantes, porém, quando nos voltamos para o grau de escolaridade, essa variedade praticamente desaparece, já que os empreendedores de rua se concentram em dois grupos: os que concluíram apenas o ensino fundamental ou os que concluíram o ensino médio. Esses dados estão diretamente relacionados à faixa etária e ao tempo de trabalho desses comerciantes e prestadores de serviços de rua: os que possuíam idades mais avançadas declararam algumas vezes não terem sequer concluído o ensino fundamental, enquanto os mais jovens possuíam o segundo grau completo.

Há uma grande presença de vendedoras e prestadoras de serviços nas ruas do centro em detrimento de empreendedores de rua do sexo masculino. Esses números foram recorrentes nas ruas analisadas, porém há de se notar que a maior parte dos vendedores que se recusaram a responder o questionário era constituída por homens. Sendo assim, existe a possibilidade de que essa diferença entre os sexos seja menor, porém, a partir das observações de campo, ainda assim haveria mais mulheres do que homens trabalhando nas ruas do entorno da Estação da Lapa em Salvador.

Observou-se também que há no mesmo espaço jovens trabalhando lado a lado de pessoas com idade mais avançada. Apesar dessa proximidade entre grupos etários, a presença de um ou outro varia de acordo com a rua pesquisada e o tempo em que o empreendedor está estabelecido naquele ponto; há uma maior presença de jovens em ruas mais afastadas da Estação da Lapa e, nas 
ruas próximas, ocorre o contrário. Uma das possíveis explicações para esse processo se encontra na reforma da Estação, que proporcionou a abertura de novas passagens de acesso às ruas do centro, que agora se tornaram palco de disputa entre os empreendedores, assim como uma oportunidade de trabalho, ainda que precário.

A distância percorrida por esses comerciantes e prestadores de serviços até seu local de trabalho também é surpreendente, já que há pessoas que saem todas as manhãs de periferias distantes do centro para seus pontos nos arredores da Estação da Lapa. Há uma grande quantidade de comerciantes e prestadores de serviços que se deslocam de bairros populares localizados na área denominada como "miolo" de Salvador, a exemplo do bairro de Sussuarana. Entre os bairros de residência, encontramos casos de pessoas que moram no Bosque das Bromélias (a 30 quilômetros do centro) e que trabalham no entorno da Lapa há mais de 10 anos. O que esses dados mostram claramente é que a maior parte desses comerciantes não reside em áreas próximas de onde trabalham e estabeleceu uma relação de territorialização/lugarização (SERPA, 2019) com seus pontos, por conta do tempo e das possíveis relações de pertencimento já formadas/consolidadas naqueles espaços.

Há uma quantidade maior de comerciantes do que de produtores no entorno da Estação. Além disso, apesar de constatada a presença de prestadores de serviços nas ruas, muitos não quiseram responder os questionários, resultando em um baixo número deles entre os respondentes. Outra questão a ser considerada aqui é a dificuldade de aferir quem realmente paga a taxa cobrada pelo município para estabelecerem seus pontos, ou seja, o Documento de Arrecadação Municipal DAM -, pois existe uma imprecisão muito grande nos valores relatados nos questionários. Com relação ao pagamento do DAM, observamos que a maior parte dos comerciantes afirma realizar o pagamento dessas taxas; porém, a frequência de pagamento e o valor dessas taxas não são informados com a clareza necessária para uma análise mais apurada; por isso, criamos classes a partir do que foi dito pelos comerciantes e prestadores de serviços, para se ter uma noção (aproximada) de quanto eles pagam de taxas para a Prefeitura (a maioria dos entrevistados - 70\% afirmou pagar entre 60 e 360 reais de taxas anuais). Assim, admite-se que há uma grande possibilidade de que essas taxas não estejam sendo pagas e a veracidade dessas informações seja passível de questionamento.

O comércio de produtos de feira (frutas e verduras) é predominante na Avenida Joana Angélica, enquanto os acessórios e as barracas de alimentos mostraram-se grandemente presentes nas ruas do entorno da Estação. Os vestuários estão também presentes em grande quantidade, inclusive muitos desses comerciantes não possuíam estruturas, expondo seus produtos diretamente no chão da calçada (Figura 2). Observe-se que poucos comerciantes deste segmento se dispuseram a responder o questionário, provavelmente por questões de irregularidades quanto ao pagamento das 
taxas da Prefeitura. Quando questionados se eram produtores ou apenas comerciantes, as respostas que eram apenas comerciantes foram quase unânimes. Isso mostra que se trata de um mercado de revenda de produtos do circuito superior - em alguns casos de modo ilegal - pelo circuito inferior da economia (SANTOS, 2004). Essa ideia é reforçada quando se observou que alguns produtos (sobretudo eletroeletrônicos) são no geral importados de países como a China ou das fronteiras brasileiras com países da América do Sul.

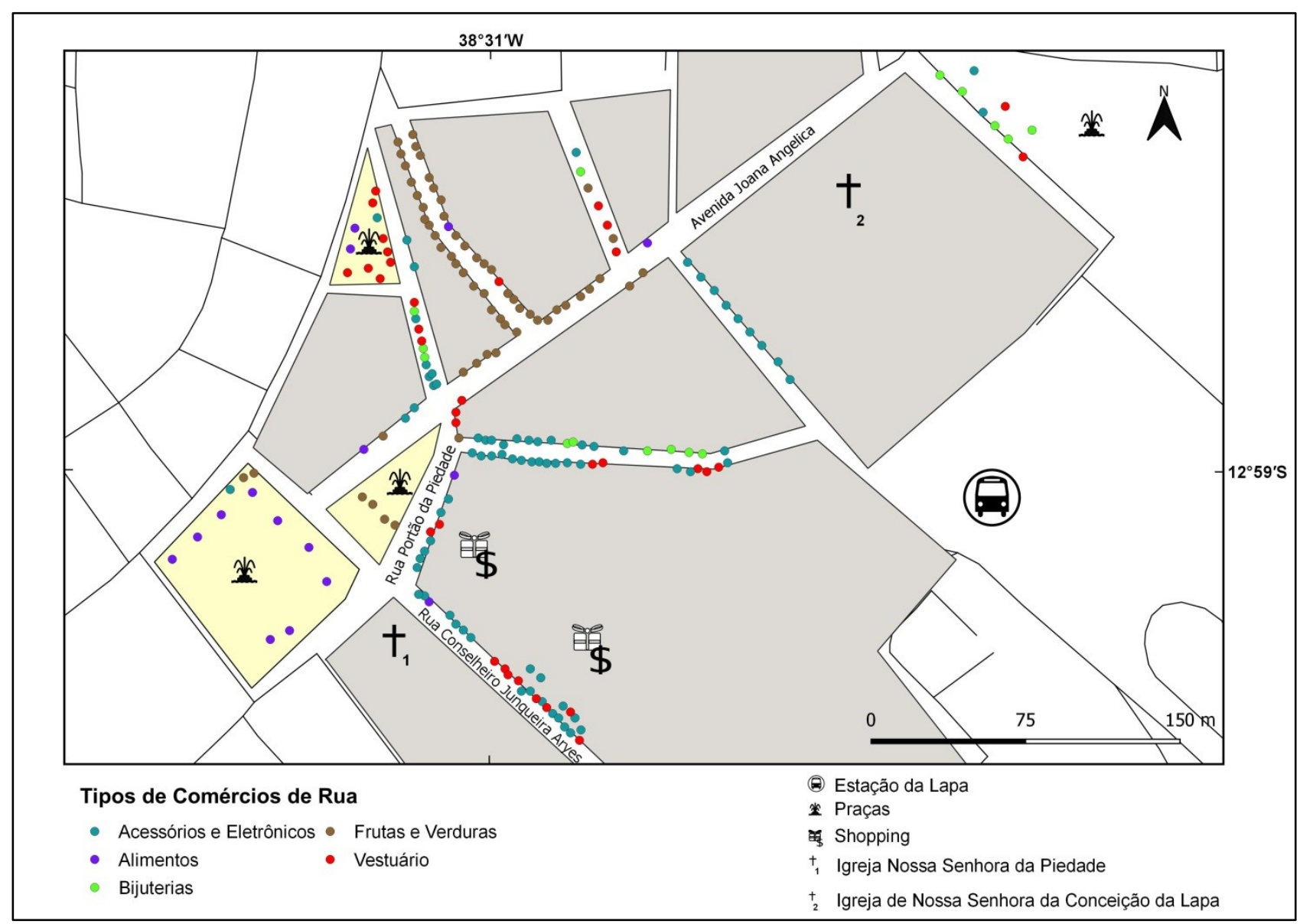

Figura 2 - Comércio e serviços de rua no entorno da Estação da Lapa, Salvador-BA.

Fonte: Autores (2019).

Em relação à renda dos comerciantes, ela varia bastante a depender do produto/serviço que eles ofereçam. Aqui, calculamos a renda diária e multiplicamos pelos seis dias de trabalho dos comerciantes, para termos uma noção aproximada de quanto é o lucro final desses trabalhadores. A maior parte dos empreendedores de rua recebe em média aproximadamente $\mathrm{R} \$ 2.000$ como renda mensal. Assim, podemos observar que é uma renda que está um pouco acima de um salário mínimo, mas não se trata de valor exorbitante e nem mesmo justo para as 12 horas diárias de trabalho sem descanso, férias ou direitos trabalhistas. Esse fato é ainda mais gritante para aqueles que recebem em média 50 reais por dia, pois esses trabalhadores têm as mesmas horas de trabalho que os demais. Existe também uma relação direta entre aqueles que recebem mais de 200 reais por dia e o 
pagamento do DAM, assim como com uma certa imprecisão quanto à origem de seus produtos. Assim, pode-se afirmar que quanto mais regularizado for o empreendedor de rua quanto ao pagamento de taxas, menor é sua renda ao final do mês.

\section{SOBRE AS OPERAÇÕES DE REQUALIFICAÇÃO E SEUS IMPACTOS SOBRE O COMÉRCIO E OS SERVIÇOS DE RUA: COTIDIANO DE DIFICULDADES}

A requalificação da Estação da Lapa teve suas obras encerradas em 29 de março de 2016 e foi executada em 14 meses, com investimentos de R \$ 20 milhões. Após a reforma, o terminal passou a contar com banheiros climatizados, onze escadas rolantes, dois elevadores, 64 lojas e equipamentos de combate a incêndio. Setenta e quatro funcionários passaram a reforçar a segurança da Estação; também foram instaladas 100 câmeras de monitoramento e nova iluminação com 450 lâmpadas.

As obras de requalificação do trecho de litoral compreendido entre as praias de Itapuã e Piatã, dentro do projeto Nova Orla, da Prefeitura Municipal, se encerraram em 23 de outubro de 2015. Nos 3,1 quilômetros de calçadão foram instalados 12 quiosques e 20 outras estruturas de menor porte para venda de alimentos diversos. Os quiosques, concebidos em três dimensões diferentes com mesas e sombreiros, além de banheiros e chuveiros, são explorados, desde então, por um período de 15 anos, pelas empresas Salvador Kiosk e Turismo Ltda., Nova Orla SPE Ltda. e Tuvalu Turismo SPE Ltda., vencedoras da licitação e que vão desembolsar cerca de $\mathrm{R} \$ 5,2$ milhões à Prefeitura pela utilização desses espaços comerciais.

Tanto nas áreas centrais, como nos trechos de orla requalificados nos últimos anos na cidade, os antigos comerciantes e prestadores de serviços de rua foram remanejados para outros locais durante a execução das obras com promessas de retorno, após sua conclusão, aos pontos originais. Mas não foi o que de fato ocorreu. Em Piatã, os ocupantes das estruturas instaladas no calçadão são novos permissionários das empresas concessionárias licitadas, sem participação dos antigos "barraqueiros", baianas de acarajé e vendedores de coco da faixa de areia. No entorno da Estação da Lapa poucos foram os empreendedores de rua que conseguiram retornar aos seus antigos pontos após sua reinauguração.

No entanto, para os comerciantes e prestadores de serviços na praia de Piatã, a requalificação do calçadão com a instalação de novas estruturas parece ter afetado pouco seu cotidiano de trabalho. Observou-se que a demolição das barracas de praia em 2010 persiste como muito impactante nas respostas desses comerciantes e prestadores de serviços, apesar de ter sido um episódio anterior à requalificação mais recente. Este ainda é um acontecimento marcante nas falas de quem trabalhava com as barracas de praia antes de 2010. Quem tinha uma relação antiga com esse trecho de orla sentiu-se muito afetado, entretanto, quem chegou depois da demolição argumenta que nada mudou com a derrubada: 
Mudou tudo, hoje a gente não é mais barraqueiro, somos ambulantes com o isopor, na barraca a gente tinha tudo, toda uma estrutura, toda uma vida e agora a gente está trabalhando no isopor tendo que comprar gelo todo dia (Sra. H. B. ${ }^{2}$, entrevista realizada em 06 de abril em 2019).

Pra gente que não tinha barraca, não mudou... Mudou pra quem tinha barraca ou que abandonou ou foi passando para quem tinha conhecido (Sr. D. C., entrevista realizada em 04 de maio em 2019).

Mudou muito porque com as barracas tinha mais cliente, tinha mais gente então mudou tudo (Sra. L. S., entrevista realizada em 06 de abril em 2019).

Mudou tudo porque você vendia tira-gosto, vendia tudo, seus peixes, seu caranguejo, sua lambreta e hoje em dia você não come um caranguejo, uma lambreta, a gente pede no restaurante, mas não sai nem lambreta nem caranguejo (Sr. J. L., entrevista realizada em 27 de maio em 2019).

Hoje ela caiu quase 50\%. Quando tinha barraca, minha barraca tinha cento e trinta mesas e quando era domingo, por volta de meio dia ou uma hora da tarde, não tinha uma mesa vazia para o cliente sentar, tinha que esperar um sair para outro sentar; hoje você trabalha com vinte mesas e a barraca vive sempre vazia com a mesma atenção que dei à clientela, o pessoal antigo sumiu todo mundo... está melhorando um pouquinho agora que eles liberaram as cadeiras plásticas para o pessoal sentar (Sr. C. R., entrevista realizada em 04 de abril em 2019).

Como já mencionado, observou-se que mais de cinquenta por cento dos comerciantes e prestadores de serviços em Piatã trabalham como "barraqueiros" há mais de dez anos e continuam nos mesmos espaços onde se encontravam as antigas barracas de praia antes da demolição. Percebese também que, mesmo com as dificuldades enfrentadas e que perduram até os dias atuais com a demolição das barracas, obtivemos respostas de comerciantes que não deixariam a praia, que gostam de sua ocupação, consideram-se ainda como "barraqueiros" e reivindicam melhores condições de trabalho. Mas, há também exceções, como é o caso da Sra. H. B.: "Mudaria porque hoje a crise econômica que a gente está vivendo não dá para manter a família da gente só trabalhando na praia".

Paz (2007, p. 312-314) discorre sobre as antigas barracas de praia e o dia a dia do trabalho dos barraqueiros. Segundo o autor, "[seu] modelo físico é indissociável dos produtos e serviços oferecidos, e demandas que têm para tanto", isto é: preparação de alimentos in loco, bebidas industrializadas guardadas em freezer, presença de chuveiros e sanitários, espaço para guardar seus materiais etc., revelando um relativo conforto tanto para os clientes quanto para os comerciantes.

Entretanto, mesmo com as características fixas das antigas barracas de praia, é uma atividade que operava e ainda opera em condições extremamente desfavoráveis. Precisa-se lidar com o tempo protegendo o cliente em épocas de chuva; é um negócio que funciona geralmente somente durante o dia; maior afluxo de clientes nos finais de semana e poucos ou raros clientes nos

\footnotetext{
${ }^{2}$ Todos os entrevistados tiveram sua identidade preservada neste artigo e são identificados com iniciais maiúsculas fictícias.
} 
dias de semana. Um cotidiano que se tornou ainda mais difícil com a retirada das barracas fixas (Figura 3).

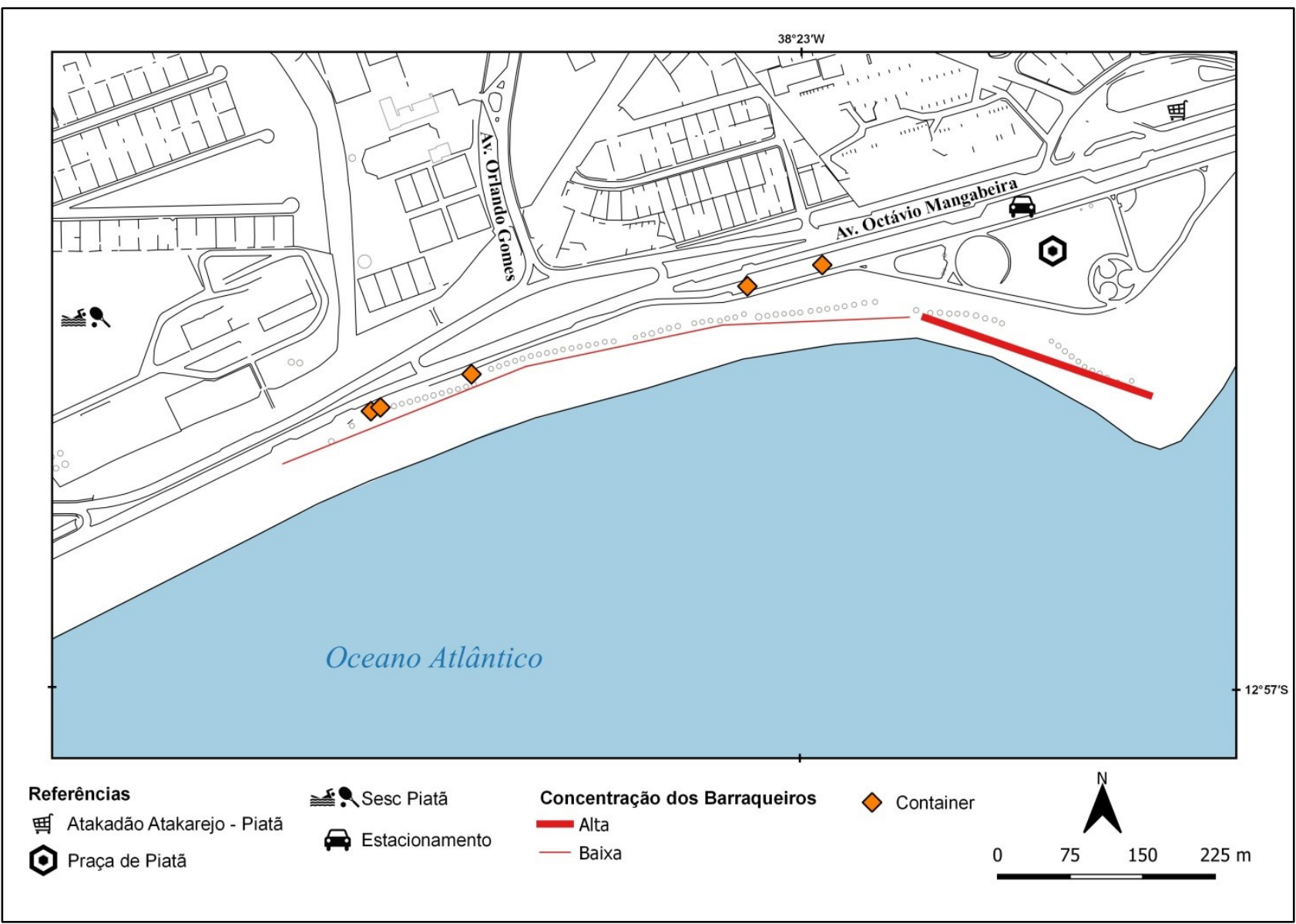

Figura 3 - Comércio e serviços de rua na orla/praia de Piatã, Salvador-BA.

Fonte: Autores (2019).

Atualmente, quem trabalha na praia de Piatã precisa desenvolver táticas ${ }^{3}$ para atrair o cliente e se adequar à nova realidade: Uma estrutura de características semifixas; caixa de isopor utilizada para guardar as bebidas; sacos de gelo que são comprados todos os dias; sombreiros e cadeiras em uma quantidade pré-estabelecida pela Prefeitura e que precisam ser retirados no final do dia. Uma realidade que engloba a todos, sem exceções. Atrair o cliente com a estrutura atual, trabalhando de forma geral com os mesmos produtos - cerveja, água de coco, água mineral, refrigerante - e impossibilitados de preparar alimentos, torna-se um grande desafio.

\footnotetext{
3 “A tática não tem por lugar senão o do outro. E por isso deve jogar no terreno que lhe é imposto (...) ela opera golpe por golpe, lance por lance" (CERTEAU, 1994, p. 100). As táticas seriam, portanto, os métodos praticados em uma espécie de guerrilha do cotidiano, demonstrando uma utilização hábil do tempo, através de movimentos rápidos, que vão mudar a organização do espaço. Elas são um contraponto para as estratégias, vistas como ações que resultam de certo poder sobre o lugar e o transforma naquilo que Certeau vai chamar de um "próprio" (SERPA, 2011). As estratégias elaboram e criam lugares segundo "modelos abstratos" e práticas tecnocráticas, enquanto as táticas enunciam lugares a partir de ações “desviacionistas”, sendo ambas localizáveis no tempo e no espaço (CERTEAU, 1994, p. 92).
} 
Para atrair o cliente e vender seus produtos, a tática mais observada entre os "barraqueiros" é abordar diretamente as pessoas nos pontos de ônibus ou ainda no estacionamento, como afirma o Sr. D. C.: "a gente faz a recepção dos clientes no estacionamento". As baianas de acarajé, para atrair os clientes, oferecem os produtos diretamente nas mesas, como afirma a Sra. B. J., referindo-se a sua ajudante: "ela faz as bandejas e desce para oferecer nas mesas". Quando questionados como ocorre a fiscalização - primeiro da Prefeitura e, em seguida, da Vigilância Sanitária - na orla de Piatã, "barraqueiros" e baianas de acarajé assim se posicionaram:

\begin{abstract}
A fiscalização é normal, quando passa aqui verifica o DAM - Documento de Arrecadação Municipal [...] não, a vigilância sanitária não existe porque não trabalha mais com alimentos (Sr. D. C., entrevista realizada em 04 de maio em 2019).

Normal. Eu tenho o meu cadastro arrumado, não me incomodo em nada [...] não existe vigilância sanitária aqui, porque não pode vender mais nada de tira-gosto, só água de coco, refrigerante e cerveja. Tudo em lata descartável e a gente bota e tira todo dia (Sr. J. L., entrevista realizada em 27 de maio em 2019).
\end{abstract}

Sempre, sempre eles aparecem aqui, é uma relação muito boa tanto para a fiscalização quanto para a vigilância (Sra. L. S., entrevista realizada em 06 de abril em 2019).

Foram observadas, portanto, diferenças nas falas dos "barraqueiros" e das baianas de acarajé: enquanto os primeiros afirmam que a vigilância sanitária não atua na praia de Piatã, já que a preparação de alimentos foi proibida após a retirada das barracas de praia, as baianas afirmam que a vigilância sanitária aparece para fiscalizar a preparação de acarajés e abarás. Também foram encontradas diferenças nas falas dos entrevistados com relação às exigências para trabalhar em Piatã. Os "barraqueiros" mencionam a obrigatoriedade do pagamento/recolhimento do DAM, além de se comprometerem a trabalhar com o material estabelecido, recolher as estruturas e os produtos no final do dia etc. As baianas de acarajé revelam exigências em relação à preparação de alimentos, com relação à higiene e também ao pagamento do DAM:

Material de qualidade, o espaço correto de cada ambulante e pagar o DAM (Sr. A. E., entrevista realizada em 25 de maio em 2019).

A prefeitura só pede para a gente trabalhar no padrão que eles exigem com os sombreiros e as quantidades de cadeiras da cor que eles querem. Vender só bebida em lata e não pode fazer comida na praia (Sra. H. B., entrevista realizada em 06 de abril em 2019).

Panela tampada, toalha de mesa limpa, não pode pintar a unha, tem que cortar a unha... tudo isso, não pode pintar a boca, nem os olhos e tem que usar lenço na cabeça. Os tomates têm que ser bem lavados, não pode pegar no acarajé e em dinheiro, lavar as mãos, né? Por causa da bactéria, né? (Sra. B. J., entrevista realizada em 18 de maio em 2019). 
O comerciante/o prestador de serviços de rua precisa ser notado, assim ele tende a se instalar onde há uma grande concentração de atividades comerciais e de serviços, ou mesmo em locais onde há aglomerações causadas pelo transporte público ou de qualquer outra natureza, lugares que exerçam centralidade na cidade (MAIA, 2013). Para isso, é necessário que as ruas e os equipamentos públicos estejam em boas condições para fomentar o fluxo de consumidores e os empreendedores consigam exercer sua ocupação.

A requalificação da Estação da Lapa, em 2015, possibilitou a construção de novos espaços para o comércio e a abertura de novas saídas de acesso para outros pontos do centro da cidade. Assim, o fluxo de transeuntes se tornou intenso em ruas que antes não apresentavam tanta movimentação, o que seria, em tese, para os comerciantes/prestadores de serviços do entorno, uma razão para comemorar. A requalificação buscou também tornar o entorno da Lapa mais organizado e, por conta disso, algumas ruas receberam manutenção, com a instalação de iluminação e toldos para proteger da chuva e do sol.

Essas mudanças tiveram um impacto bastante positivo para os empreendedores, ao menos é o que descrevem quando questionados sobre a atual situação da Lapa; porém, aqueles que estão um pouco mais afastados das áreas onde ocorreram reformas afirmam que a falta de ordenamento na localização dos comerciantes/prestadores de serviços é o principal problema enfrentado por eles:

Eu acho que ela melhorou muito depois da "Nova Lapa", principalmente aqui. Aqui tinha muito mais assalto, muito mais dificuldade, as pessoas vinham raramente procurar algum produto para comprar, melhorou, com certeza (Sra. V. U., entrevista realizada em 19/03/2019 - Praça Carneiro Ribeiro).

Muito bagunçada, bagunça total. Aqui nesse calçadão ainda é mais tranquilo, porque não armaram todas as barracas, mas na Joana Angélica como um todo está horrível (Sra. C. B., entrevista realizada em 14/05/2019 - Avenida Joana Angélica).

Observa-se nas falas dos comerciantes/prestadores de serviços que há descontentamento com o ordenamento das barracas. Uma das comerciantes chega a afirmar que "tem mais vendedores nas ruas do que compradores e isso atrapalha", mostrando que o problema não está apenas na ausência de ordenamento, mas no número de empreendedores de rua que cresceu consideravelmente nos últimos tempos. Esse número elevado de comerciantes/prestadores de serviços de rua, consequência do aumento do número de desempregados na cidade, faz com que a concorrência seja um dos maiores desafios para o trabalho nas ruas do entorno da Lapa:

Rapaz é cada dia tentar trabalhar com os nossos concorrentes, porque aqui todo mundo precisa. Então nosso maior desafio é que, mesmo que sejam as mercadorias iguais, é importante procurar vencer a cada dia (Sra. R. Q., entrevista realizada em 09/04/2019 Avenida Joana Angélica). 
Todos, porque tem rapa, tem seguranças, tem tudo o que você imaginar aqui. O que você imaginar (Sra. J. I., entrevista realizada em 14/05/2019 - Rua Portão da Piedade).

Essa relação conflituosa entre os concorrentes tende a ser mais intensa nas ruas onde a SEMOP - Secretaria Municipal da Ordem Pública não atua constantemente, ou quando os fiscais fazem "vista grossa" diante da ausência de ordenamento. Outra questão-chave quanto aos motivos que levaram à intensificação dos conflitos entre os empreendedores é se isso já ocorria antes da requalificação da Lapa, pois há ali empreendedores com pontos fixos há mais de vinte anos. Para responder essa inquietação quanto à constante (re)territorialização, que apareceu do início ao fim em nossas pesquisas, perguntamos aos comerciantes/prestadores de serviços se a requalificação da Lapa havia afetado seus negócios de alguma maneira, fosse direta ou indiretamente. É interessante que, nessas respostas, os empreendedores observam que foram afetados diretamente quando precisaram ser relocados durante o período da requalificação, mas eles não associam em nenhum momento a presença dos novos comerciantes/prestadores de serviços com a retirada dos cento e cinquenta empreendedores do interior da Estação da Lapa. A requalificação também surge como positiva para aqueles que estavam fixados em pontos que anteriormente apresentavam pouco movimento:

O comércio caiu muito, muito. Quando fez aquela reforma de lá e depois essa daqui mesmo, todo mundo baratinado, os clientes não sabiam onde você estava. Até você localizar de novo deu trabalho. Quem tinha telefone se encontrava, a gente dizia onde tava, mas que prejudicar muito, prejudicou. Teve muita gente que, para lhe falar a verdade, até ponto perdeu. Porque não teve condições de arcar com as mercadorias e acabou a guia também. Muita gente não se ergueu por causa disso, pois guia pequena geralmente o cara vende e come (Sr. A. Z., entrevista realizada em 14/05/2019 - Rua Vinte e Um de Abril).

A fala do Sr. A. Z. é importante por abrir um novo viés de reflexão, pois ele afirma que não foram apenas os comerciantes/prestadores de serviços que se localizavam dentro da Estação que não conseguiram se relocar, já que o período da requalificação também foi um fator de quebra de negócios e expulsão dos empreendedores do entorno. Paralelamente, a fala da Sra. I. H. demonstra que a requalificação é justamente o que manteve o negócio dela em atividade. Observase nessas falas, assim como em todas as outras, que a localização dos comerciantes/prestadores de serviços é um fator de extrema importância para se buscar entender a relação que eles têm com a requalificação: aqueles que estão nas ruas que servem de entrada e saída para a Estação parecem aprovar a reforma, ao contrário daqueles localizados em ruas mais distantes como, por exemplo, a Vinte e Um de Abril. Com o aumento do número de vendedores/prestadores de serviços concentrados em pontos específicos do entorno da Lapa, coube a cada empreendedor encontrar novas formas de venda. Os comerciantes/prestadores de serviços demonstram em suas falas que as 
táticas para atrair clientes são inevitáveis pela própria essência da atividade na rua, mesmo que sua efetividade seja baixa e o retorno menor do que o esperado:

Não tem 'mais' venda, porque a concorrência é muito grande. É disputada! Cada produto que eu vendo, outra pessoa vende o mesmo produto que eu, então uma empata a outra de vender. O custo da venda é baixíssimo, a gente vem pra rua para se aventurar (Sra. J. I., entrevista realizada em 14/05/2019 - Rua Portão da Piedade).

A gente sempre tem que colocar uma coisa que não tenha igual. A gente tenta, mas não adianta, você vê uma mercadoria aqui hoje e no outro dia já tem outro alguém vendendo. A gente tem que sempre inovar (Sra. C. D., entrevista realizada em 14/03/2019 - Rua Conselheiro Junqueira Ayres).

Na primeira etapa da pesquisa, a aplicação dos questionários revelou que as mercadorias vendidas na rua eram réplicas compradas nas "lojas dos chineses", assim como pela internet ou em centros de distribuição, o que se comprova na fala da Sra. C. D.: com a ausência de variedade na oferta de produtos, restam aos empreendedores de rua, como únicas táticas possíveis para atrair os clientes, a qualidade do serviço oferecido e a localização do ponto.

A afirmação de um dos entrevistados - "é como matar um leão por dia" - define bem a rotina desses trabalhadores, pois, para além do problema da concorrência, comum para quem trabalha com comércio em geral, os empreendedores enfrentam problemas com os agentes do poder público que, apesar de agir como intermediadores entre a Prefeitura e os comerciantes/prestadores de serviços de rua, em alguns momentos representam a razão de suas dificuldades. A Secretaria de Ordem Pública, a SEMOP, é o órgão da Prefeitura responsável pelo ordenamento e pela fiscalização do comércio e dos serviços das ruas. Para não ter problemas com a fisscalização da SEMOP é exigido do comerciante/prestador de serviço que ele esteja em dia com o Documento de Arrecadação Municipal e seu negócio tem que estar localizado onde o agente o alocou. Quando questionamos sobre a quem recorrer em caso de eventuais problemas que possam surgir no ponto, os vendedores apontaram a responsabilidade da SEMOP, tanto em caso de organização/ordenamento quanto em casos de apreensão de materiais: "Olha a gente tem que ir até a Prefeitura, no setor da SEMOP, que é o setor que cuida das barracas. De início, eles é quem têm que resolver" (Sra. C. B., entrevista realizada em 14/05/2019 - Avenida Joana Angélica).

Essa relação dúbia com a fiscalização, com momentos de conflitos e de trabalho conjunto, se assemelha aos efeitos da requalificação. Porém, o principal conflito entre os empreendedores tem origem no pagamento do DAM: cadastrados combatem a presença dos não cadastrados diariamente, e, por conta disso, os comerciantes/prestadores de serviços cobram maior fiscalização da SEMOP

\footnotetext{
${ }^{4}$ Termo genérico aplicado ao comércio atacadista presente no Centro Antigo de Salvador (especialmente na Avenida Sete de Setembro), que, na verdade, agrega comerciantes de outras nacionalidades (coreanos, por exemplo), mas também brasileiros. Aqui, pode-se pensar que algumas dessas empresas também apresentam características do circuito superior marginal (SANTOS, 2004).
} 
para os colegas não cadastrados. As falas dos comerciantes quando questionados sobre a relação que possuem com o órgão é de constante cobrança e denúncia:

Rapaz, é que essa rua aqui tem segurança, tem o segurança aqui dessa rua. Aí geralmente não tem, lá tem, lá pra baixo tem, porque quando o rapa começa a perturbar... Ali você descendo ali nesses camelôs ali na frente, ali ninguém tem licença pra nada, mas aqui a gente tem, a gente paga o DAM. Aí pronto, não tem perturbação. Quando eles vêm é pra recadastrar, “cadê seu DAM?", só isso. Porque aqui é o seguinte: tem o “organizador”, que sempre passa aqui e organiza. Aí nunca teve problema para a gente chegar a reclamar, mas é aquilo que eu tava te falando: pra lá tem porque eles não têm ponto fixo, um bota no ponto do outro, aí começa aquela guerra, o rapa vem e é uma confusão (Sr. A. Z., entrevista realizada em 14/05/2019 - Rua Vinte e Um de Abril).

Só digo que eles têm que arrumar a rua porque a rua tá muito bagunçada, esse pessoal da fruta aí que trabalha sem camisa, sem nada, entendeu? Hoje em dia se a gente não tem segurança aqui, se a gente não paga segurança separado, estaria muito pior. Porque a Prefeitura não está dando muito apoio à gente, que é cadastrado (Sr. M. L., entrevista realizada em 19/03/2019 - Rua Portão da Piedade).

A presença de uma suposta segurança privada chama atenção, pois em duas ruas diferentes os vendedores/prestadores de serviços encontraram uma solução em conjunto para resolver o problema dos assaltos que costumam ocorrer naquelas áreas. Isso abre um questionamento quanto à existência de um sindicato atuante, ou alguma forma de organização social entre os vendedores/prestadores de serviços. Esses indícios já apareciam desde a etapa de aplicação dos questionários, mas, até a conclusão da pesquisa, todos os nomes de sindicato indicados pelos entrevistados não puderam ser confirmados/localizados. Outra questão crucial é entender que, por melhor que seja a relação entre os poderes públicos e os comerciantes/prestadores de serviços, tratase aqui da apropriação de espaços de uso comum, uma vez que o empreendedor de rua necessita de lugares de grande fluxo para sua espacialização, deflagrando um processo de territorialização/privatização dos logradouros públicos e ficando para o Estado a responsabilidade de ordenar o espaço urbano dentro dos parâmetros previstos no planejamento (MAIA, 2013).

\section{PARA NÃO CONCLUIR: REIVINDICAÇÕES, DESEMPREGO E OS DOIS CIRCUITOS DA ECONOMIA URBANA}

Do ponto de vista dos entrevistados, Piatã se encontra em situação precária, o que traz empecilhos tanto para quem trabalha quanto para quem frequenta a praia. Nesse contexto, os comerciantes e prestadores de serviços ponderaram também o que eles consideram necessário para melhorar seu local de trabalho e atrair mais clientes:

Uma escada para a gente ter acesso à praia, uma rampa para deficiente, banheiro de qualidade e até mesmo um lugar para a gente guardar os materiais porque esses containers a gente paga (Sr. A. E., entrevista realizada em 25 de maio em 2019). 
Água potável tanto para o comerciante quanto para a população tomar banho, uma estrutura melhor para a gente trabalhar porque a gente tenta se proteger com um sombreiro (Sra. H. B., entrevista realizada em 06 de abril em 2019).

Eu acho que devia fazer uns quiosques para melhorar a situação da praia porque a praia é um lazer para todos, mas da forma que está tirou a clientela da praia porque só esses sombreiros pequenos, a gente tem que levar todo dia e aí o material quebra, se tivesse uns quiosques guardava o material lá dentro, fechava e ia embora. Agora você tem que pagar transporte, container, para poder manter o material que fica levando e trazendo, assim não tem material que aguente (Sr. C. R., entrevista realizada em 04 de abril em 2019).

A principal reivindicação é que eles colocassem uns quiosques, mini quiosques para cada um, mas eles nunca vão colocar mesmo, para a praia ficar mais bonita e evitar que a gente bote e tire os materiais, a reivindicação é só essa (Sr. D. C., entrevista realizada em 04 de maio em 2019).

As reivindicações revelam a falta de uma estrutura fixa para trabalhar, que possibilite aos comerciantes guardar seus materiais, evitando sua retirada no final do dia ou um custo adicional para guardá-los em containers privados. Além disso, se preocupam com o conforto oferecido a seus clientes ao reivindicarem banheiros, água potável e chuveiros. Também os comerciantes e prestadores de serviços do entorno da Estação querem, antes de tudo, que a estrutura física instalada durante a reforma seja revista. Afirmam que principalmente o toldo que lhes serve de teto torna a estadia nos pontos insuportável - também para os consumidores - por conta do calor do sol; afirmam que algumas estruturas já estão se desgastando, necessitando de reparos. A organização das ruas também aparece aqui - ela é a segunda reivindicação mais mencionada nas falas dos comerciantes/prestadores de serviços:

Olha, essa cobertura aí que deixa a gente louca quando faz calor, é muito quente, horrível (Sra. C. B., entrevista realizada em 14/05/2019 - Avenida Joana Angélica).

Pra mim seria realmente melhorar essa cobertura, eu não acho que seja uma cobertura ideal para as pessoas ficarem o dia inteiro, então tem condições de melhorar uma cobertura aqui, pois esse material ajuda só na chuva, mas esquenta demais (Sra V. U., entrevista realizada em 19/03/2019 - Praça Carneiro Ribeiro).

É mister constatar que, para alguns comerciantes e prestadores de serviços de rua do entorno da Estação da Lapa (e também da orla de Piatã), a principal reivindicação seja uma simplória manutenção da infraestrutura pública para a continuidade de seu cotidiano de trabalho. Isso aponta também para a fragilidade do circuito inferior, composto por indivíduos que se encontram impossibilitados de custear a manutenção do patrimônio público.

Santos (2004) reconheceu que a dinâmica econômica dos países subdesenvolvidos era mediada por dois circuitos da economia: o circuito superior é aquele produzido pelos setores modernos, representados pelos bancos, pela indústria de exportação, pelos grandes comerciantes, pelos serviços avançados, pelo comércio atacadista e pelas empresas de transporte; enquanto o 
circuito inferior é uma reação às contradições geradas pelo circuito superior, ou seja, ele é constituído por formas de capital não intensivo, basicamente formado pelos comerciantes/prestadores de serviços de rua, pelos estabelecimentos formais de comércio de pequena dimensão ou qualquer atividade que exija maiores quantidades de trabalho manual.

Um dos circuitos é o resultado direto da modernização tecnológica. Consiste nas atividades criadas em função dos progressos tecnológicos e das pessoas que se beneficiam deles. $\mathrm{O}$ outro é igualmente um resultado da mesma modernização, mas um resultado indireto, que se dirige aos indivíduos que só se beneficiam parcialmente ou não se beneficiam dos progressos técnicos recentes e das atividades a eles ligadas (SANTOS, 2004, p. 38).

Os dois circuitos são produto das contradições criadas pelo modo de produção capitalista, através do qual a riqueza é inevitavelmente criadora de uma enorme massa de pobres nos grandes centros urbanos. Entender a dinâmica dos dois circuitos da economia aparenta ser a chave para a compreensão do que ocorreu com os comerciantes/prestadores de serviços de rua durante a requalificação da Estação da Lapa. Esses empreendedores, localizados no entorno de shoppings e grandes lojas, expressam na paisagem a indissociabilidade dos dois circuitos da economia, a centralidade sendo criada a partir da atração exercida pelo circuito superior. Essa indissociabilidade também pode ser observada entre os "barraqueiros" de Piatã e os depósitos e distribuidores de bebidas, demonstrando a grande dependência entre o comércio e os serviços de rua e o comércio atacadista/as empresas distribuidoras do circuito superior. Se bem que no caso de algumas dessas empresas possa-se pensar em um circuito superior "marginal", devido aos níveis de técnica e capital envolvidos, assim como ao porte dos estabelecimentos e à mão de obra pouco especializada (SANTOS, 2004).

É importante pontuar aqui que a informalidade é apenas um dos aspectos do comercio/dos serviços de rua (SERPA, 2018), pois no entorno da Estação da Lapa e na praia de Piatã há comerciantes/prestadores de serviços que pagam taxas à Prefeitura, estão localizados de acordo com as determinações da SEMOP e possuem pontos fixos com barracas/estruturas padronizadas pelo Poder Municipal. Desse modo,

a teoria dos dois circuitos da economia vem suprir uma lacuna em Geografia ao tratar da economia popular nos países subdesenvolvidos, revelando a inconsistência do uso da categoria 'informalidade', considerada por Santos como insuficiente para explicar a dialética entre os dois circuitos (SERPA, 2018b, p. 452).

É preocupante (e lamentável) que o poder público tenha prometido o retorno dos comerciantes a seus pontos no interior da Estação da Lapa, assim como tenha alimentado expectativas entre os "barraqueiros" e baianas de acarajé em Piatã para a possibilidade de ocuparem os quiosques/estruturas instalados no calçadão da orla, na reforma de 2015, como noticiado em 
veículos de comunicação impressa e televisiva, e que, ao final das operações de reforma, essas expectativas não tenham sido cumpridas.

A requalificação da Estação da Lapa é resultado de uma Parceria Público-Privada, enquanto os quiosques e estruturas do calçadão de Piatã foram concedidos à exploração de empresas privadas, não sendo compromisso das empresas cumprir qualquer promessa realizada pela Prefeitura aos vendedores/prestadores de serviços da Lapa ou de Piatã, o que provoca um conflito de interesses entre o poder público, a iniciativa privada e os cidadãos, esses desprovidos de capital e colocados como obstáculos no processo de privatização da infraestrutura pública instalada.

Sendo o circuito superior representado por aqueles que detêm capital, os episódios de requalificação aqui analisados se apresentam como a sobreposição da territorialidade dos poderes públicos e da iniciativa privada sobre aquela dos comerciantes/prestadores de serviços do circuito inferior, ou, em outras palavras, a expulsão (e des-territorialização) “de cima para baixo” do circuito inferior pelo circuito superior de determinados espaços, da Estação e de seu entorno bem como da orla/da praia de Piatã.

Ressalte-se que a presença/a resistência dos comerciantes/prestadores de serviços de rua é também um ato político, pois esses empreendedores ressignificam as ruas no momento em que se veem na "sombra" do desemprego. No caso específico do entorno da Estação, os empreendedores possuem necessidades distintas a depender da sua localização no espaço, mas a crise econômica e o aumento do desemprego são fenômenos que contribuem para a intensificação dos conflitos por território. Segundo o último relatório da PNAD, a Bahia se encontra em segundo lugar entre os estados brasileiros com a maior taxa de desemprego ${ }^{5}$, em um cenário que não apresenta nenhum sinal de mudança positiva, uma vez que as políticas neoliberais do governo federal visam a uma maior flexibilização das relações trabalhistas e, consequentemente, uma ainda maior precarização da mão de obra.

Oscilando entre táticas de territorialização e lugarização (SERPA, 2019), frente às estratégias de requalificação urbana dos poderes públicos, comerciantes e prestadores de serviços de rua se veem ameaçados em seus espaços de trabalho na capital baiana. Se, em Piatã, a continuidade de sua atuação, mesmo com a derrubada das barracas fixas em 2010, foi transformando território

\footnotetext{
5 “Sobre a taxa de desocupação, de 18,3\% no $1^{\circ}$ trimestre de 2019, a Bahia ficou atrás apenas do Amapá (20,2\%), mas bem acima da média nacional, de 12,7\%. É a segunda maior taxa de desocupação para o estado desde o início da série histórica da PNAD Contínua (em 2012), abaixo apenas da verificada no $1^{\circ}$ trimestre de 2017 , de $18,6 \%$. Na Região Metropolitana de Salvador, a taxa de desocupação do $1^{\circ}$ trimestre ficou em 18,7\%, maior que a do $4^{\circ}$ trimestre de 2018 $(17,3 \%)$, mas abaixo da verificada no $1^{\circ}$ trimestre do ano passado (19,2\%). Mesmo assim, foi a $3^{\text {a }}$ maior desocupação entre as regiões metropolitanas do país: perde para a de Macapá (20,4\%) e São Luís (19,7\%). Já Salvador fechou o primeiro trimestre do ano com uma taxa de desocupação de 15,8\%. A capital baiana registrou, entre janeiro e março, um aumento de 16 mil novos ocupados em relação ao mesmo período do ano passado" ("Taxa de desemprego na Bahia sobe e chega a 18,3\% no primeiro trimestre do ano", Correio 24 horas, 17/05/2019. https://www.correio24horas.com.br/noticia/nid/taxa-de-desemprego-na-bahia-sobe-e-chega-a-183-no-primeirotrimestre-do-ano/, acesso em 25 de Agosto de 2019.
} 
em lugar, pela permanência resiliente e apesar das adversidades impostas pelo poder público, no entorno da Lapa territórios ameaçados continuamente pela concorrência e pela atuação da fiscalização vão impondo, em seu dia a dia de violência e trabalho duro, táticas frequentes de reterritorialização que afastam a emergência do entorno da Lapa como lugar no imaginário dos empreendedores de rua.

\section{REFERÊNCIAS}

CERTEAU, M. A invenção do cotidiano. 2. ed. Petrópolis: Vozes, 1994. 320p.

MAIA, A. C. N. Circuitos e redes do comércio de rua em Salvador, Bahia: Uma análise geográfica. 2013. 131 f. Dissertação (Mestrado em Geografia) - Instituto de Geociências, Universidade Federal da Bahia, Salvador, 2013.

PAZ, D. J. M. O Território no Vazio: Os usos na praia do Jardim de Allah ao farol de Itapuã. 2008. Dissertação (Mestrado em Arquitetura e Urbanismo) - Faculdade de Arquitetura e Urbanismo, Universidade Federal da Bahia, Salvador, 2008.

SANTOS, M. O Espaço Dividido. 2. ed. São Paulo: EDUSP, 2004. 440p.

SERPA, A. Por uma Geografia dos espaços vividos. 1. ed. Geografia e Fenomenologia. São Paulo: Editora Contexto, 2019. 128p.

SERPA, A. Comércio de rua e requalificação de espaços públicos em Salvador-Bahia: uma agenda de pesquisa. Revista Geografares, Vitória, v. 26, p. 53-68, 2018 a.

SERPA, A. Contribuições teóricas para a pesquisa urbana: Milton Santos e a teoria dos dois circuitos da economia. In: SERPA, A.; CARLOS, A. F. A. (Org.). Geografia urbana: desafios teóricos contemporâneos. Salvador: EDUFBA, 2018b. p. 449-458.

SERPA, A. Lugar e Mídia. 1. ed. São Paulo: Editora Contexto, 2011. 192p.

Pesquisa Nacional por Amostra de Domicílios Contínua - PNAD Contínua/IBGE. Disponível em: $<$ https://www.ibge.gov.br/estatisticas/sociais/trabalho/9173->. Acesso em: 12 jun. 2019.

Trabalho enviado em 04/09/2019

Trabalho aceito em $01 / 10 / 19$ 